\title{
Study on the mechanism of the Pu-erh tea (Camellia sinensis var. assamica) extract inhibiting contraction of isolated mouse duodenum
}

\author{
Ailong Sha ${ }^{1}$, Haiyan $\mathrm{Hao}^{2}$ \\ Chongqing Three Gorges University, ${ }^{1}$ School of Teacher Education, ${ }^{2}$ School of Environmental \\ and Chemical Engineering, Wanzhou, Chongqing, People's Republic of China
}

Received December 30, 2020

Accepted August 31, 2021

\begin{abstract}
The aims of this study were to investigate the effects of three different concentrations of the Pu-erh tea extract (PTE) on the contractile activity of the isolated mouse duodenum and explore their mechanism. The contraction amplitude and frequency of the isolated mouse duodenum were inhibited by all three concentrations of PTE. The high-concentration PTE significantly $(P<0.01)$ inhibited the promotion effects of acetylcholine chloride or BayK8644 on the amplitude and frequency of intestinal contraction, which were comparable to those of atropine sulphate and verapamil hydrochloride, respectively. The results of UV-Vis and ELISA showed that the content of methionine-enkephalin (Met-ENK) in the PTE-treated groups was decreased to varying degrees; contrarily, the activities of tyrosine hydroxylase (TH), total nitric oxide synthase, and the content of nitric oxide were increased to different degrees. The results suggest that PTE can inhibit the contraction of the isolated mouse duodenum, and the mechanism of action is that PTE can not only inhibit the signal transduction pathways of AC-cAMP-PKA and PLC-IP $-\mathrm{Ca}^{2+}$, but also the $\mathrm{Ca}^{2+}$ signal systems mediated by $\mathrm{G}$ proteincoupled $\mathrm{M}$ receptors through the myenteric plexus. By reducing the release of Met-ENK from the motor neurons of the myenteric plexus, the GTP-cAMP-PKK signalling pathway and the $\mathrm{Ca}^{2+}$ signalling system mediated by $\mathrm{G}$ protein-coupled delta receptors were inhibited. By increasing the $\mathrm{TH}$ activity of the motor neurons in the myenteric plexus, the norepinephrine content was increased, thereby the AC-cAMP-PKA signal transduction pathway mediated by $\mathrm{G}$ protein-coupled $\beta$ receptors was activated. This study increases knowledge regarding the medicinal value of the Pu-erh tea.
\end{abstract}

Neurotransmitters, signal pathways, myenteric plexus, $\mathrm{Ca}^{2+}$

$\mathrm{Pu}$-erh tea (Camellia sinensis var. assamica) is a woody plant of the Camellia family, which is mainly produced in areas with Pu'er, Menghai, and Gengma in the Yunnan Province as the core (Jeong et al. 2020). Studies have shown that the main components of $\mathrm{Pu}$-erh tea include tea pigments, tea polyphenols, tea polysaccharides, theanine, alkaloids, flavonoids, etc. (Lv et al. 2016). Pu-erh tea is a kind of post-fermented tea, which can not only protect the gastric mucosa (Yang et al. 2018), but also has significant pharmacological anti-cancer (Xie et al. 2017), antioxidant (Choi et al. 2019), antiarteriosclerosis (Xiao et al. 2019), bacteria-inhibiting (Ewelina et al. 2019), dietetic and weight-loss (Xia et al. 2019; Lu et al. 2019), cognitive impairment (Jeong et al. 2020), and anti-inflammatory (Huang et al. 2020) effects. It has been reported that plant extracts can inhibit the contraction of the small intestine (An et al. 2018; Nigusse et al. 2019), and the preliminary experiments of our research group have found that the Pu-erh tea extract (PTE) can also inhibit duodenal contraction. In view of the fact that the effect of the PTE on duodenum contraction has not been reported yet, this experiment intends to study the effect and mechanism of the PTE on isolated duodenal contraction in mice, so as to provide new ideas for the research and development of new drugs, as well as theoretical basis for the treatment of gastrointestinal motility disorders and new clinical uses of $\mathrm{Pu}$-erh tea.

\footnotetext{
Address for correspondence: 


\section{Materials and Methods}

Animals

A total of 70 healthy adult Kunming mice ( $n=35$ for each sex), weighing 18-22 g, were provided by Hunan Slake Jingda Experimental Animals Co., Ltd (production license number SCXK (Xiang) 2019-0004, Changsha, Hunan, China). All mice were housed in conventional cages with free access to standard food and water. The care and use of mice were approved by the Scientific Ethics Committee for Experiments on Animals of the Chongqing Three Gorges University. All applicable international, national, and institutional guidelines for the care and use of animals were followed. All of the protocols on living animals used in this study came from Hunan Slake Jingda Experimental Animals Co., Ltd (production license number SCXK (Xiang) 2019-0004, Changsha, Hunan, China). Moreover, all efforts were made to minimize the suffering of the mice.

Chemicals and reagents

The Pu-erh tea used was prepared tea that had been purchased from the Anning Bay Tea Industry Co., Ltd. (Anning, Yunnan, China). Protease inhibitors and Bay K8644 were obtained from Sigma Chemical Co. (St. Louis, MO, USA). Acetylcholine chloride (ACh), atropine sulphate (ATPs) and verapamil hydrochloride (VRP) were purchased from the Sinopharm Chemical Reagent Co., Ltd. (Shanghai, China). Commercial kits used for the determination of total nitric oxide synthase (TNOS), nitric oxide (NO), Coomassie brilliant blue protein were purchased from the Nanjing Jiancheng Bioengineering Institute (Nanjing, China). Methionine-enkephalin (Met-ENK) ELISA kit was from Shanghai Jingkang Bioengineering Co., Ltd. (Shanghai, China). Tyrosine hydroxylase (TH) ELISA kit was from Prosci Co., Poway, CA, USA. All reagents used in preparation of Locke's solution ( $\mathrm{KC} 10.42 \mathrm{~g}, \mathrm{NaCl} 9 \mathrm{~g}, \mathrm{NaHCO}_{3} 0.2 \mathrm{~g}, \mathrm{CaCl}_{2} 0.24 \mathrm{~g}$, glucose $1.0 \mathrm{~g}$, and distilled water $1000 \mathrm{ml}$ ) were analytically pure, purchased from the Sinopharm Chemical Reagent Co., Ltd.

Preparation of the PTE

The preparation procedure of the PTE was improved according to the method of Wang et al. (2016). Pu-erh tea leaves ( $6 \mathrm{~g}$, passed through a 40-mesh sieve) were accurately weighed and soaked in boiling distilled water $\left(100{ }^{\circ} \mathrm{C}\right)$ three times, $30 \mathrm{~min}$ each time. The filtrate was combined and concentrated to $100 \mathrm{ml}$, and a high concentration of the PTE $(60 \mathrm{mg} / \mathrm{ml})$ was obtained. Then after diluting two times, medium and low concentrations of 30 and $15 \mathrm{mg} / \mathrm{ml}$, respectively, were obtained.

Preparation of isolated mouse duodenal smooth muscle and recording its contractile activity

The mice were sacrificed by cervical dislocation. The abdominal cavity was opened quickly, the residual duodenal contents were expelled to the jejunum, and a $1-2 \mathrm{~cm}$ long duodenal segment was taken after separating the mesentery along the edge. The intestinal section was washed repeatedly in Locke's solution and then both ends of the section were ligated with silk threads. The lower end of the intestinal segment was fixed on an L-shaped hook at the bottom of the test tube in the constant temperature smooth muscle trough (Chengdu Taimeng Software Co., Ltd., Chengdu, China). The upper end was connected to the elastic beam of the tension transducer (Chengdu Taimeng Software Co., Ltd., Chengdu, China) by silk thread, and 1-2 bubbles were pumped into the bottom of the test tube every second through the built-in air pump in the constant temperature smooth muscle trough. The contraction curve of the intestinal segment was collected and recorded by the BL-420F biological signal acquisition and processing system (Chengdu Taimeng Software Co., Ltd., Chengdu, China). After $20 \mathrm{~min}$ of stabilization, the experiment was started. The recorded indicators included the contraction amplitude and frequency.

In the experiment, the low-concentration PTE was added into the test tube, after being recorded and observed, it was rinsed 3 times with $37{ }^{\circ} \mathrm{C}$ Locke's solution. After the contraction curve was restored, the medium and high-concentration PTEs were added in the same way. They were recorded and observed for 15 min with the contraction curve before adding the medicine as a control. The effects of different concentrations of the PTE on the contraction amplitude and frequency of the isolated mouse duodenum were recorded and analysed, and the inhibition rates were calculated as follows:

Inhibition rate $(\%)=$ mean value before and after dosing/mean value before dosing $\times 100 \%$

In order to explore the mechanism of the PTE's effects on duodenal smooth muscle contraction, the following experiments were designed by the methods described below.

Acetylcholine chloride induction experiment

Acetylcholine chloride $(0.1 \mu \mathrm{mol} / 1)$ was added into the test tube when the duodenal contraction curve of mice was stable, and the high-concentration PTE $(60 \mathrm{mg} / \mathrm{ml})$ was added after $5 \mathrm{~min}$. During this period, the changes of the isolated duodenal contraction frequency and amplitude were observed and recorded. Atropine sulphate $(1 \mu \mathrm{mol} / \mathrm{l})$ was used as a positive control.

Bay K8644 induction experiment

When the intestinal segment contraction curve of mice was stable, $\mathrm{CaCl}_{2}(0.1 \mu \mathrm{mol} / \mathrm{l})$ was added into the test tube. The high-concentration PTE was added after $5 \mathrm{~min}$ and changes in the contraction frequency and amplitude of the isolated duodenum in mice were observed and recorded. Verapamil hydrochloride $(0.1 \mu \mathrm{mol} / \mathrm{l})$ was used as a positive control. 
Determination of the TNOS activity and NO content

A total of 40 mice were randomly divided into 4 groups: the control group and the PTE-treated groups of the low, medium, and high concentrations. The isolated duodenal smooth muscle specimens of mice in each group were prepared and soaked with Locke's solution and low, medium, and high concentrations of PTE. The intestinal segments were cut into pieces after $15 \mathrm{~min}$. Parts of the duodenal tissues were placed in 9-fold pre-cooled saline, and a $10 \%$ tissue homogenate was prepared by ice bath homogenisation for $10 \mathrm{~min}$. After centrifugation at $3000 \mathrm{~g}$ for $10 \mathrm{~min}$, the supernatant was taken, the activity of TNOS and the contents of NO and proteins in each group were determined by the respective detection kits UV-Vis (Aoyi Instruments Shanghai Co., Ltd., Shanghai, China).

Preparation of duodenal tissues for enzyme-linked immunosorbent assay (ELISA)

The isolated duodenum segments in each group were washed with precooled phosphate buffered saline (PBS, $0.01 \mathrm{M}, \mathrm{pH}=7.4)$, then the tissues were cut up after weighing. The cut tissues and PBS of corresponding volume (based on the weight volume ratio of 1:9, it was recommended to add protease inhibitor into PBS) were added into a glass homogenizer which was grounded on ice. Finally, the homogenate was centrifuged at $5000 \mathrm{~g}$ for 5 min and supernatant was detected.

\section{ELISA}

The reaction programs of ELISA were carried out according to the TH and Met-ENK ELISA kit instructions. Finally, $50 \mu \mathrm{l}$ termination solution was added into each hole of a 96 well microtitre plate for $15 \mathrm{~min}$, and the optical density (OD) values were measured at the wavelength of $450 \mathrm{~nm}$ using an iMark Microplate Reader (Bio-Rad, Hercules, California, USA). Then, the OD values were substituted into the linear regression equation, the TH activity and the Met-ENK content of the samples were calculated.

\section{Statistical analysis}

The program IBM SPSS Statistics 23.0 (SPSS Inc., Chicago, IL, USA) was used for experimental data processing. The results were expressed as the mean plus or minus standard deviation (SD). Paired $t$-test was used to compare the differences between the two groups before and after administration. One-way ANOVA was used to compare the differences between the experimental and control groups, and Dunnett's $t$-test was used for further comparisons between groups. Differences were regarded as significant at $P<0.05$, highly significant at $P<0.01$.

\section{Results}

Effects of the PTE on the contraction amplitude of isolated mouse duodenum

As shown in Table 1 and Fig. 1, compared to the values before administration, the three doses of PTE had an inhibitory effect on the contraction amplitude of the isolated mouse duodenum, and the difference was significant in the low-concentration group $(P<0.05)$ and highly significant in the medium- and high-concentration groups $(P<0.01)$. The inhibition rate $(23.68 \%, 33.33 \%$, and 41.67 , respectively) was gradually increased with the increase of the PTE concentration, which showed a certain dose-dependent effect.

A

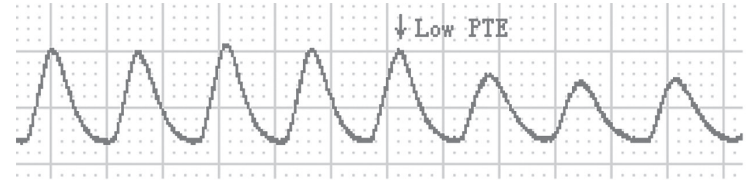

B
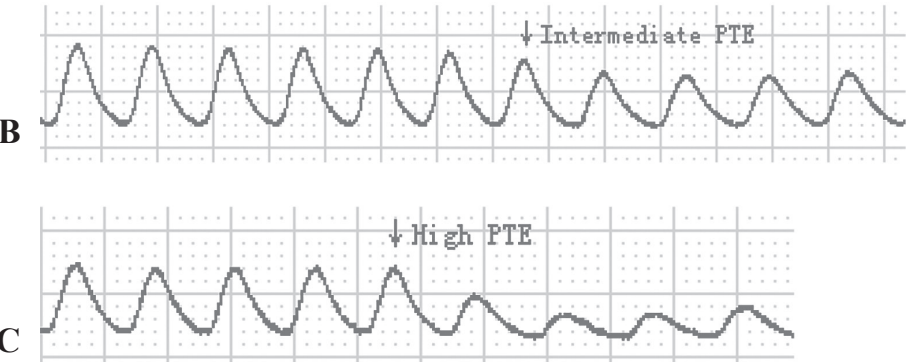

Fig. 1. Effects of the Pu-erh tea extract (PTE) on the contraction of the isolated mouse duodenum 
Table 1. Effects of the PTE on the contractile amplitude of isolated mouse duodenum (mean $\pm \mathrm{SD}, \mathrm{n}=10$ ).

\begin{tabular}{lcccc}
\hline \multirow{2}{*}{ Group } & $\begin{array}{c}\text { Concentrations } \\
\left(\mathrm{mg} \cdot \mathrm{ml}^{-1}\right)\end{array}$ & \multicolumn{2}{c}{ Contractile amplitude $(\mathrm{g})$} & Inhibition rate (\%) \\
\cline { 3 - 4 } & 15 & $0.38 \pm 0.06$ & $0.29 \pm 0.03^{*}$ & 23.68 \\
Low PTE & 30 & $0.36 \pm 0.03$ & $0.24 \pm 0.02^{* *}$ & 33.33 \\
Intermediate PTE & 60 & $0.36 \pm 0.02$ & $0.21 \pm 0.04^{* *}$ & 41.67 \\
High PTE & & Before administration & After administration & \\
\hline
\end{tabular}

PTE - Pu-erh tea extract

${ }^{*} P<0.05,{ }^{* *} P<0.01$ compared to the values with before administration

Table 2. Effects of the PTE on the contractile frequency of isolated mouse duodenum (mean $\pm \mathrm{SD}, \mathrm{n}=10$ )

\begin{tabular}{lcccc}
\hline \multirow{2}{*}{ Group } & $\begin{array}{c}\text { Concentrations } \\
\left(\mathrm{mg} \cdot \mathrm{ml}^{-1}\right)\end{array}$ & \multicolumn{2}{c}{ Contraction frequency $\left(\right.$ times $\left.\cdot \mathrm{min}^{-1}\right)$} & Inhibition rate $(\%)$ \\
\cline { 3 - 4 } & 15 & $40.25 \pm 5.06$ & $31.39 \pm 2.84^{*}$ & 22.01 \\
Low PTE & 30 & $40.18 \pm 4.73$ & $28.15 \pm 2.52^{* *}$ & 29.94 \\
Intermediate PTE & 60 & $42.09 \pm 6.17$ & $22.46 \pm 1.65^{* *}$ & 46.64 \\
High PTE & & &
\end{tabular}

PTE - Pu-erh tea extract

${ }^{*} P<0.05,{ }^{* *} P<0.01$ compared to the values with before administration

Effects of the PTE on the contractile frequency of isolated duodenum in mice Compared to the values before administration, all three PTE-treated groups $(15,30$, $60 \mathrm{mg} \cdot \mathrm{ml}^{-1}$ ) had an inhibitory effect on the contractile frequency of the isolated duodenum in mice, and the inhibitory rate $(22.01 \%, 29.94 \%$, and 46.64 individually) were gradually increased with the increase of the PTE concentration, which showed a significant dosedependent effect (Table 2, Fig. 1). The difference was significant in the low-dose group $(P<0.05)$, and very significant in the medium- and high-dose groups $(P<0.01)$.

Effects of the PTE on the contractile amplitude and frequency of isolated mouse duodenum induced by ACh

As shown in Table 3 and Fig. 2, ACh alone significantly increased the contractile amplitude $(0.54 \pm 0.05)$ and frequency $(58.91 \pm 5.39)$ of the isolated duodenum in mice compared to the values before administration $(P<0.01)$. After adding the PTE $(60 \mathrm{mg} / \mathrm{ml})$, the contractile amplitude $(0.40 \pm 0.03)$ and frequency $(45.26 \pm 3.08)$ were significantly reduced, the effect was equivalent to that of ATPs $(0.38 \pm 0.04$ and $43.51 \pm 3.29$, respectively), and the difference was highly significant compared to ACh $(P<0.01)$.

Table 3. Effects of the PTE on the contractile amplitude and frequency of the isolated mouse duodenum induced by $\mathrm{ACh}($ mean $\pm \mathrm{SD}, \mathrm{n}=10)$.

\begin{tabular}{lcccc}
\hline & Before administration & ACh & High PTE & ATPs positive control \\
\hline $\begin{array}{l}\text { Contractile amplitude }(\mathrm{g}) \\
\begin{array}{l}\text { Contraction frequency } \\
\left(\text { times } \cdot \mathrm{min}^{-1}\right)\end{array}\end{array}$ & $0.36 \pm 0.03$ & $0.54 \pm 0.05^{* *}$ & $0.40 \pm 0.03^{\# \#}$ & $0.38 \pm 0.04^{\# \#}$ \\
\hline
\end{tabular}

PTE - Pu-erh tea extract; ACh - acetylcholine chloride; ATPs: atropine sulphate

${ }_{* *}$ indicates comparison before and after administration, $P<0.01$; ${ }^{\#}$ compared to the intervention of ACh, $P<0.01$

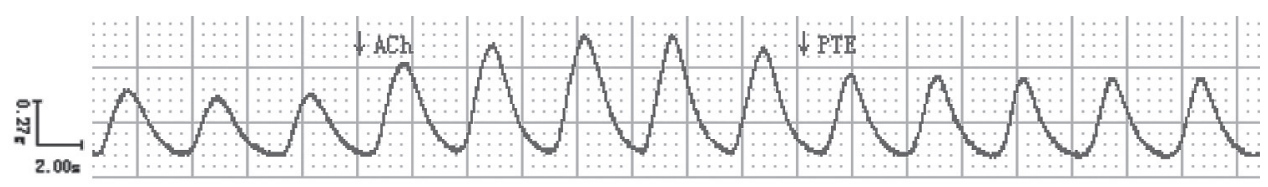

Fig. 2. Effects of the Pu-erh tea extract (PTE) on the contraction of the isolated mouse duodenum by ACh 
Effects of the PTE on the contraction amplitude and frequency of isolated duodenum in mice induced by Bay k 8644

As shown in Table 4 and Fig. 3, Bay K8644 alone significantly increased the contraction amplitude $(0.58 \pm 0.06)$ and frequency $(61.37 \pm 5.41)$ of the isolated duodenum in mice compared to the values before administration $(P<0.01)$. After adding the PTE $(60 \mathrm{mg} / \mathrm{ml})$, the contraction amplitude $(0.41 \pm 0.04)$ and frequency $(46.05 \pm 3.21)$ were significantly decreased $(P<0.01)$, and the effect was similar to that of VRP $(0.39 \pm 0.03$ and $44.37 \pm 4.08$, respectively).

Table 4. Effects of the PTE on the contractile amplitude and frequency of the isolated duodenum in mice induced by Bay $\mathrm{k} 8644($ mean $\pm \mathrm{SD}, \mathrm{n}=10)$.

\begin{tabular}{lcccc}
\hline & Before administration & Bay k8644 & High PTE & VRP positive control \\
\hline $\begin{array}{l}\text { Contractile amplitude }(\mathrm{g}) \\
\begin{array}{l}\text { Contraction frequency } \\
\left(\text { times } \cdot \mathrm{min}^{-1}\right)\end{array}\end{array}$ & $0.36 \pm 0.03$ & $0.58 \pm 0.06^{* *}$ & $0.41 \pm 0.04^{\# \#}$ & $0.39 \pm 0.03^{\# \#}$ \\
\hline
\end{tabular}

PTE - Pu-erh tea extract; VRP - verapamil hydrochloride

${ }^{* *}$ indicates comparison before and after administration, $P<0.01$; ${ }^{\#}$ compared to the intervention of Bay k8644, $P<0.01$

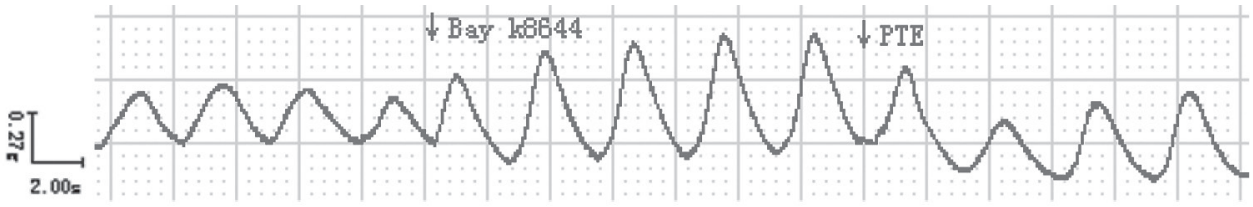

Fig. 3. Effects of the Pu-erh tea extract (PTE) on the contraction of the isolated mouse duodenum by Bay k8644

Effects of the PTE on the activities of TH, TNOS and the contents of NO and Met-ENK in isolated duodenum in mice

Compared to the control group, the Met-ENK content in the three PTE-treated groups was reduced, and the difference was highly significant in the medium- and high-concentration groups $(P<0.01)$, but non-significant in the low-concentration group $(P>0.05)$. The NO content and the activities of TH, TNOS in the three PTE-treated groups were higher than those in the control group. The differences were highly significant in the medium- and high-concentration groups $(P<0.01)$ and significant for the TNOS activity and the NO content in the low-concentration group $(P<0.05)$ but the difference for the TH activity in the low-concentration group was non-significant $(P>0.05)$ (Table 5).

Table 5. Effects of the PTE on the activities of TH and TNOS and the contents of NO and Met-ENK in the isolated mouse duodenum (mean $\pm \mathrm{SD}, \mathrm{n}=10$ ).

\begin{tabular}{lccccc}
\hline Group & $\begin{array}{c}\text { Concentration } \\
\left(\mathrm{mg} \cdot \mathrm{ml}^{-1}\right)\end{array}$ & $\begin{array}{c}\mathrm{TH} \\
\left(\mathrm{pg} \cdot \mathrm{ml} \mathbf{-}^{-1}\right)\end{array}$ & $\begin{array}{c}\text { TNOS/ } \\
(\mathrm{U} / \mathrm{mg})\end{array}$ & NO (umol/g) & $\begin{array}{r}\text { Met-ENK/ } \\
\left(\mathrm{pg} \cdot \mathrm{ml}^{-1}\right)\end{array}$ \\
\hline Control group & - & $643.19 \pm 23.05$ & $1.56 \pm 0.14$ & $2.08 \pm 0.16$ & $7.64 \pm 0.69$ \\
Low PTE & 15 & $654.61 \pm 51.47$ & $1.95 \pm 0.21^{*}$ & $2.34 \pm 0.22^{*}$ & $7.31 \pm 0.82$ \\
Intermediate PTE & 30 & $950.85 \pm 33.42^{* *}$ & $2.26 \pm 0.12^{* *}$ & $2.95 \pm 0.30^{* *}$ & $5.83 \pm 0.48^{* *}$ \\
High PTE & 60 & $1182.26 \pm 83.41^{* *}$ & $2.21 \pm 0.10^{* *}$ & $2.83 \pm 0.24^{* *}$ & $4.57 \pm 0.35^{* *}$ \\
\hline
\end{tabular}

PTE - Pu-erh tea extract; TH - tyrosine hydroxylase; TNOS - total nitric oxide synthetase; NO - nitric oxide; Met-ENK - methionine-enkephalin

${ }^{*}$ significant difference $(P<0.05),{ }^{* *}$ highly significant difference $(P<0.01)$ compared to the control groups 


\section{Discussion}

Similar to skeletal muscle, the duodenal smooth muscle contraction is also excitedcontracted coupling triggered by the sarcolemmal action potential, and the trigger factor is also $\mathrm{Ca}^{2+}$. The difference is that there are two pathways of electrical-mechanical coupling and drug-mechanical coupling in the regulation of $\mathrm{Ca}^{2+}$ concentration (Wang 2018). Electrical-mechanical coupling causes the L-type calcium channels $\left(\mathrm{I}_{\mathrm{Ca}}\right)$ in the muscle membrane to release extracellular $\mathrm{Ca}^{2+}$ into the cytoplasm, and $\mathrm{Ca}^{2+}$ binds to calmodulin $(\mathrm{CaM})$ to form a complex, which triggers myofilament sliding and causes the duodenal smooth muscle contraction. Drug-mechanical coupling is caused by exogenous drugs that generate inositol triphosphate $\left(\mathrm{IP}_{3}\right)$ by activating the $\mathrm{G}$ protein-coupled receptor phospholipase $\mathrm{C}$ (PLC)-IP 3 signalling pathway and eventually mediate the release of $\mathrm{Ca}^{2+}$ into the cytoplasm from the sarcoplasmic reticulum. The results of this study showed that the three PTE-treated groups could inhibit the contraction frequency and amplitude of the isolated duodenum in mice, which may be because: 1) The PTE can inhibit extracellular $\mathrm{Ca}^{2+}$ influx and $\mathrm{Ca}^{2+}-\mathrm{CaM}$ signalling pathway by inhibiting $\mathrm{I}_{\mathrm{Ca}-\mathrm{L}}$ of the muscle membrane; 2) The PTE can inhibit the G protein-coupled receptor-mediated PLC-IP $-\mathrm{Ca}^{2+}$ signal transduction pathway; 3) The PTE can inhibit the release of intracellular $\mathrm{Ca}^{2+}$ (Wang 2018). The duodenal activity is influenced by neurological and humoral factors. Humoral factors include many kinds of ion channels and receptors on the cell membrane of the duodenal smooth muscle. When messenger molecules activate ion channels or when neurotransmitters and exogenous drugs combine with receptors on the membranes, the signal transduction pathway of smooth muscle cells will change and thus regulate its movement. The nerve factors include the regulation of the external nerves (sympathetic and parasympathetic) and the enteric nervous system. Although the external nerves were lost in the isolated duodenum of the mice, the enteric nervous system still existed (Sanders 1996). The enteric nervous system is composed of two layers of nerve structures in the gastrointestinal tract wall, containing a large number of neurons and nerve fibres, which can be divided into the myenteric plexus and the submucosal nerve plexus. The submucosal nerve plexus mainly regulates the functions of the epithelial cells and glandular cells, whereas the myenteric plexus between the circular and longitudinal muscles mainly controls the activities of smooth muscles (Furness 2016). The smooth muscle movement of the duodenum is mainly regulated and controlled by the myenteric plexus. The neurons that make up the myenteric plexus regulate the duodenal movement by releasing different neurotransmitters. These neurotransmitters can be divided into two categories. Excitatory neurotransmitters such as enkephalin (ENK), Ach, and 5-hydroxytryptamine can promote the duodenal movement (Wang et al. 2019), and inhibitory neurotransmitters such as norepinephrine (NE), adrenaline, NO and secretin can inhibit it (Furness 2016).

Acetylcholine chloride is an excitatory neurotransmitter that is involved in regulating the duodenal motility. When binding to the $\mathrm{G}$ protein-coupled $\mathrm{M}$ receptor on the duodenal muscle membrane, Ach activates adenylate cyclase (AC) to increase intracellular concentration of cyclic adenosine monophosphate (cAMP), activates protein kinase A (PKA) and $\mathrm{I}_{\mathrm{Ca}-\mathrm{L}}$ (Huang et al. 2019), which increases the extracellular $\mathrm{Ca}^{2+}$ influx, resulting in the enhancement of the duodenal smooth muscle contraction (Wallace et al. 2013). Bay K8644 is an activator of $\mathrm{I}_{\mathrm{Ca}-\mathrm{L}}$, which can promote a large amount of extracellular $\mathrm{Ca}^{2+}$ into the cells and enhance the contraction of the duodenal smooth muscle (Zhang et al. 2013). When the PTE was added, the contraction effect was significantly inhibited $(P<0.01)$. Therefore, it is inferred that the PTE can block $\mathrm{I}_{\mathrm{Ca}-\mathrm{L}}$, inhibit the external $\mathrm{Ca}^{2+}$ influx induced by the Bay K8644, and then inhibit the contraction of the isolated mice duodenum. The results showed that the PTE could 
significantly $(P<0.01)$ inhibit the promotion effects of Ach or BayK8644 on the amplitude and frequency of the intestinal contraction, and the inhibition effects were comparable to those of ATPs and VRP, which were the commonly used M-choline receptor blockers and $\mathrm{I}_{\mathrm{Ca}-\mathrm{L}}$ blockers, respectively. Therefore, it is suggested that the PTE can not only inhibit the signal transduction pathways of AC-cAMP-PKA and PLC-IP $-\mathrm{Ca}^{2+}$, but also the $\mathrm{Ca}^{2+}$ signal systems (such as, inhibit $\mathrm{I}_{\mathrm{Ca}-\mathrm{L}}$ of the muscle membrane and then inhibit the $\mathrm{Ca}^{2+}-\mathrm{CaM}$ signalling pathway) mediated by $\mathrm{G}$ proteincoupled $\mathrm{M}$ receptors.

Enkephalin is also an excitatory neurotransmitter that is involved in regulating the duodenal motility, which belongs to the endogenous opioid neuropeptide family, mainly including Leu-ENK and Met-ENK. Our previous studies have shown that ENK is the endogenous ligand of the delta opioid receptor (Sha et al. 2013). Enkephalin can activate guanosine triphosphate (GTP) binding proteins on the duodenal muscle membrane by binding to the $G$ protein-coupled delta receptor (Chakrabarti et al. 1998), which increases the intracellular concentration of cAMP and activates the $\mathrm{Ca}^{2+}$-dependent protein kinase C (PKC) and protein kinase K (PKK) (Heagy et al. 1999), and then activates the $\mathrm{Ca}^{2+}$ signalling systems (Martin and Gabrilovac 1999), resulting in an increase of the duodenal smooth muscle contraction. Tyrosine hydroxylase is a ratelimiting enzyme for NE synthesis, which can be used as a marker of NE neuronal activity. The increase of TH expression directly leads to the increase of NE synthesis (Armaz et al. 2019). Norepinephrine is an adrenergic beta receptor agonist, which is an inhibitory neurotransmitter of the duodenal motility. It can relax the duodenal smooth muscle by activating the $\mathrm{G}$ protein-coupled $\beta$ receptor-mediated AC-cAMP-PKA signal transduction pathway. Nitric oxide synthase (NOS) is a synthetase of NO. When binding with $\mathrm{Fe}^{2+}$ in haemoglobin, NO activates guanylate cyclase (GC) to increase the concentration of cyclic guanosine phosphate (cGMP) (Ignarro et al. 1982), activates protein kinase G (PKG) and causes the phosphorylation of related proteins, which decreases the intracellular $\mathrm{Ca}^{2+}$ concentration and inhibits the contraction of the duodenal smooth muscle (Melamed et al. 1976). The results of UV-Vis and ELISA showed that compared to the control group, the content of Met-ENK in the isolated duodenal myenteric plexus of the three PTE-treated mice was decreased to varying degrees, and contrarily, the activities of $\mathrm{TH}$, TNOS, and the content of NO were increased to different degrees. The results suggested that the PTE may affect the duodenal motility by regulating the activity of motoneurons in the duodenal myenteric plexus. The PTE can inhibit the GTP-cAMP-(PKK or PKC) signalling pathway and the $\mathrm{Ca}^{2+}$ signalling system mediated by $\mathrm{G}$ protein-coupled delta receptors by reducing the content of Met-ENK, thereby inhibiting the isolated duodenal contraction. It can increase NE by increasing the TH activity, and then activate the AC-cAMP-PKA signal transduction pathway mediated by $\mathrm{G}$ protein-coupled $\beta$ receptors, thereby relaxing the isolated duodenal smooth muscle. It can promote the synthesis of gaseous neurotransmitter NOby promoting the release of NOS from the motor neurons in the myenteric plexus, thus activating the enzyme-linked receptor-mediated GC-cGMP-PKG signal transduction pathway, finally leading to weakening of the isolated duodenal contraction.

Based on the results of this study, it can be seen that the PTE can inhibit the contraction of the isolated duodenum in mice through the myenteric plexus. The mechanism of inhibition is related to the regulations of the release of different neurotransmitters and the transductions of different signal pathways. It can be concluded that the PTE can inhibit the gastrointestinal spasm, relieve gastrointestinal pain, resist severe peristalsis of an injured intestine, and is effective in the treatment of gastrointestinal motility diseases such as diarrhoea, abdominal pain, and gastrointestinal spasm. The results of this study increase knowledge regarding the medicinal value of $\mathrm{Pu}$-erh tea. 


\section{Acknowledgements}

The authors are pleased to acknowledge the financial support of this research by the Sichuan Education Department of China (18ZB0636, 17ZB0469), Science and Technology Research Project of the Chongqing Education Commission (KJQN201901235, KJQN2020).

\section{References}

An Y, Song GM, Liu DL, Mao TY, Zhao YM, Xie WL 2018: Analysis of the main constituents of Changshu tablet and its spasmolysis effect against contraction induced by acetylcholine in the rat-isolated intestinal smooth muscle. Pak J Pharm Sci 31: 835-840

Armaz A, Adama B, Jeffrey AK, Jenna RG, Anthony EG, Barry BK 2019: Angiotensin II mediates the axonal trafficking of tyrosine hydroxylase and dopamine $\beta$-Hydroxylase mRNAs and enhances norepinephrine synthesis in primary sympathetic neurons. J Neurochem 150: 666-677

Chakrabarti S, Wang L, Tang WJ, Gintzler AR 1998: Chronic morphine augments adenylyl cyclase phosphorylation: relevance to altered signaling during tolerance/dependence. Mol Pharmacol 54: 949-953

Choi SH, Kim ID, Dhungana SK, Park K 2019: Effect of extraction temperature on physicochemical constituents and antioxidant potentials of Pu-erh tea. Korean J Food Sci Technol 51: 584-591

Ewelina J, Piotr K, Paweł K, Katarzyna TĆ, Lesław J 2019: Intelligent and active furcellaran-gelatin films containing green or pu-erh tea extracts: Characterization, antioxidant and antimicrobial potential. Int J Biol Macromol 122: 745-757

Furness JB 2016: Integrated neural and endocrine control of gastrointestinal function. The enteric nervous system. Berlin: Springer International Publishing, pp. 1-15

Heagy W, Teng E, Lopez P, Finberg RW 1999: Enkephalin receptors and receptor-mediated signal transduction in cultured human lymphocyte. Cell Immunol 191: 34-48

Huang CS, Wu HY, Li YY, He TT, Chen W 2019: Effect of huomaren decoction on contraction mechanism of rabbit small intestinal smooth muscle. Clin J Tradit Chin Med 31: 1312-1316

Huang YN, Qiu L, Mi X, Zhang ZH, Xu D, Tao XY, Xing KY, Wu QL, Wei H 2020: Hot-water extract of ripened $\mathrm{Pu}$-erh tea attenuates DSS-induced colitis through modulation of the NF- $\kappa \mathrm{B}$ and HIF-1 $\alpha$ signaling pathways in mice. Food Funct 11: 3459-3470

Ignarro LJ, Degnan JN, Baricos WH, Kadowitz PJ, Wolin MS 1982: Activation of purified guanylate cyclase by nitric oxide requires heme comparison of heme-deficient, heme-reconstituted and heme-containing forms of soluble enzyme from bovine lung. Biochim Biophys Acta 718: 49-59

Jeong YH, Oh YC, Pak ME, Li W, Go YH, Lee JJ 2020: Pu'er tea water extract protects against cognitive impairment in a mouse model of lipopolysaccharide-induced neuroinflammation. Phytomedicine 79: 153338-153349

Lu XJ, Liu JX, Zhang NS, Fu YH, Zhang ZC, Li Yan X, Wang WQ, Li Yan Y, Shen P, Cao YG 2019: Ripened Pu-erh tea extract protects mice from obesity by modulating gut microbiota composition. J Agr Food Chem 67: 6978-6994

Lv HP, Zhang Y, Yang T, Shi J, Lin Z 2016: Comparative study on the content levels of the major chemical constituents of Pu-erh tea among different producing areas. Sci Technol Food Ind 37: 59-64, 68

Martin KI, Gabrilovac J 1999: The effect of $\delta$-opioid agonists on intracellular calcium level in MOLT-4 T-cell line. Int J Immunopath $\mathrm{Ph}$ 12: 113-119

Melamed E, Lahav M, Atlas D 1976: Direct localisation of beta-adreno-ceptor sites in rat cerebellum by a new fluorescent analogue of pro-pranolol. Nature 261: 420-432

Nigusse T, Zhang L, Wang R, Wang XN, Li JX, Liu CY 2019: Flavonoids in a crude extract of Catha edulis inhibit rat intestinal contraction via blocking $\mathrm{Ca}^{2+}$ channels. Neurogastroenterol Motil e13602: 1-10

Sanders KM 1996: A case for interstitial cells of Cajal as pacemakers and mediators of neurotransmission in the gastrointestinal tract. Gastroenterology 111: 492-512

Sha AL, Sun HS, Wang YY 2013: Immunohistochemical observations of methionine-enkephalin and delta opioid receptor in the digestive system of Octopus ocellatus. Tissue Cell 45: 83-87

Wallace JA, Li F, Balakrishnan S, Cantemir S, Carmen Z, Pecot T 2013: Ets2 in tumor fibroblasts promotes angiogenesis in breast cancer. PLoS One 8: e71533.

Wang C, Zhao P, Zhou YN, Wang TX and Sun HJ 2019: Chinese rice wine inhibits contraction activity of the isolated rat small intestine through intestinal myenteric plexus. Food Sci 40: 173-178

Wang TX 2018: Physiology. $9^{\text {th }}$ edn. Beijing: People's Medical Press: pp. 51-56, pp. 177-180

Wang YL, Zou YN, Zhang H 2016: Effect of Pu'er tea extract on serum uric acid in hyperuricemia mice. Nei Mongol J Tradit Chin Med 4: 98

Xia Y, Tan DH, Akbary R, Kong J, Seviour R, Kong YH 2019: Aqueous raw and ripe Pu-erh tea extracts alleviate obesity and alter cecal microbiota composition and function in diet-induced obese rats. Appl Microbiol Biot 103: $1823-1835$

Xiao YH, He M, Shu J, Yuan ZY 2019: Pu'er tea improves atherosclerosis by reducing NF-kB activity and promoting macrophage apoptosis. Hsi-An Chiao Tung Ta Hsueh 40: 847-852

Xie J, Yu HS, Song S, Fang CY, Wang XJ, Bai ZB, Ma X, Hao SM, Zhao HY, Sheng J 2017: Pu-erh tea water extract mediates cell cycle arrest and apoptosis in MDA-MB-231 human breast cancer cells. Front Pharmacol 8: 190 
Yang JN, Zhou WY, Gu YR, Dai JW, Li XX, Tai P, Li YC, Ma XH, Zhang YY 2018: Protective effect of Pu-erh tea extracts against ethanol-induced gastric mucosal damage in rats. Biomed Rep 8: 335-342

Zhang J, Shao ZW, Gao Y, Wang QY 2013: Influences of quercetin on contraction of small intestine smooth muscle of rabbits in vitro and its mechanism. Chin J Appl Physiol 29: 162-165 